\title{
Screening and PVT Analysis on Explored-Not-Productive Southern Iranian Oilfields
}

\author{
Mostafa Lashkarbolooki ${ }^{*}$, Mehdi Bayt ${ }^{2}$, Ali Zeinolabedini Hezave², \\ Shahab Ayatollahi ${ }^{3}$, Hosein Vahdani ${ }^{4}$ \\ ${ }^{1}$ School of Chemical Engineering, Babol University of Technology, Babol, Iran \\ ${ }^{2}$ Islamic Azad University, Dashtestan Branch, Borazjan, Iran \\ ${ }^{3}$ School of Chemical and Petroleum Engineering, Sharif University of Technology, Tehran, Iran \\ ${ }^{4}$ National Iranian Oil Company, Southern Zagros Oil \& Gas Production, Tehran, Iran \\ Email: "lashkar80@yahoo.com
}

Received 4 April 2015; accepted 24 April 2015; published 29 April 2015

Copyright (C) 2015 by authors and OALib.

This work is licensed under the Creative Commons Attribution International License (CC BY).

http://creativecommons.org/licenses/by/4.0/

(c) (i) Open Access

\begin{abstract}
One of the main concerns of each petroleum engineer is the selection of the best EOR method to maximize the oil production from the reservoir. In this regard, one of the explored-not-productive southern Iranian oil fields was considered as the objective of this study to find which enhanced oil recovery (EOR) method is the proper method to apply on this reservoir. Therefore, a procedure capable of combining the data extracted from different sources ranging from worldwide field experiences to the existing tables into a unified expert system is used. This expert system is based on Bayesian network analysis in order to sort the proper EOR techniques for further assessment by economical and environmental criteria. In addition, after collecting of surface samples at the gas and liquid separator, and subsequently recombined with solution gas oil ratio, several tests including constant composition expansion (CCE) (flash vaporization, flash liberation flash expansion, pressure-volume relations), differential vaporization (differential liberation differential expansion) and solubility and swelling tests were performed.
\end{abstract}

\section{Keywords}

Gas Injection, EOR, Recombination, Swelling, $\mathrm{CO}_{2}, \mathrm{~N}_{2}$

Subject Areas: Chemical Engineering \& Technology

\section{Introduction}

One of the explored-not-productive southern Iranian oilfields containing about one billion barrels of original oil

How to cite this paper: Lashkarbolooki, M., Bayt, M., Hezave, A.Z., Ayatollahi, S. and Vahdani, H. (2015) Screening and PVT Analysis on Explored-Not-Productive Southern Iranian Oilfields. Open Access Library Journal, 2: e1437.

http://dx.doi.org/10.4236/oalib.1101437 
in place (OOIP) was studied carefully. The preliminary studies revealed that it is possible to recover about two hundred and seventy million barrels of the original oil in place (OOIP) under the production rate of 30,000 bbl/day. Investigation demonstrated that the production rate declining of Iranian oil fields is about $9 \%-11 \%$ annually. So, it is necessary to drill new wells each year to keep the production rate constant which is highly expensive. In addition, due to an increasing demand of energy, more oil and hydrocarbon sources are necessary. But, while the pressure of the reservoir declines, the production rate reduces, and consequently $60 \%-80 \%$ of OOIP remains trapped in the pores of the reservoir due to viscous and capillary forces [1]. When the life of the well is over, the pressure underground will become insufficient to force oil to the surface, meaning that secondary and tertiary recovery methods need to be employed [2].

Totally, the importance of choosing the best recovery method becomes increasingly important to petroleum engineers. In recent years, computer technology has improved the application of screening criteria through the use of artificial intelligence and Bayesian techniques. The main tool for screening of enhanced oil recovery (EOR) techniques is generally based on the criteria presented in a variety of tables and graphs given in the literature. These data are derived from the basic theory of multiphase fluid flow through porous media, reservoir simulation, laboratory experiments and existing field-scale experiences [3]. A data bank has been gathered from worldwide EOR/IOR techniques and analyzed using data mining procedure which is then combined with extracted data from previously published screening tables. Bayesian network quantitative learning technique was applied to different data combinations from the data bank to train the network which is to serve as the expert system. The produced expert system is also applied to the gathered data pertaining to 10 Iranian southwest reservoirs.

In addition, the most important step of every explored-not-productive oilfield is to examine the phase behavior of the reservoir fluids. In this regard, common phase behavior experiments including constant composition expansion (CCE) (flash vaporization, flash liberation flash expansion, pressure-volume relations), differential vaporization (differential liberation differential expansion) and swelling test were carried out.

\subsection{Screening}

Generally, EOR processes are divided into four categories: thermal, gas, chemical, and other (see Table 1) [4].

As aforementioned, higher oil prices and concerns about future oil supply are leading to increased interest in Enhanced Oil Recovery (EOR) around the world. So, extensive researches have been conducted to develop various EOR methods, evaluate their applicability and optimize operation conditions [5] [6]. But, since EOR projects are generally more expensive and involve higher front end costs than conventional secondary projects, one of the principal areas is to develop an effective tool for selection of a suitable EOR method according to oil field characteristics [7]. Due to the high importance of this tool, a large number of studies have been conducted to help the petroleum engineer select efficient EOR methods with limited field information [8]-[15]. In one of

\begin{tabular}{ll} 
Table 1. Different EOR methods categories. \\
\hline \\
Steam flooding \\
Cyclic steam stimulation \\
In-situ combustion \\
Hot water flooding \\
Steam-assisted gravity drainage \\
Hydrocarbon miscible/immiscible \\
CO ${ }_{2}$ miscible \\
CO ${ }_{2}$ immiscible \\
Nitrogen \\
Flue gas (miscible and immiscible) \\
Gravity drainage \\
Chemical EOR processes & Micellar-polymer \\
& Polymer \\
& Caustic/alkaline \\
& Alkaline/surfactant \\
Gas EOR processes & Carbonated water flood \\
& Microbial \\
Other EOR processes & Electromagnetic heating \\
\end{tabular}


the first efforts, screening criteria were briefly presented in a series of tables and simple graphs [16]. Then, EOR methods were classified based on field data and EOR mechanisms [17] [18] and were updated in 2011 [19]. The main tool for screening of EOR techniques is generally based on the criteria presented in a variety of tables and graphs given in the literature. The most efficient tool was proposed by Taber et al. [16]-[18] and Goodlett et al. [20] established the technical screening criteria of each EOR method. In recent years, simulation methods, artificial intelligence and neural networks have improved the EOR screening methods. Zerafat et al. [7] solved the problem of selecting appropriate EOR methods by Bayesyan network. So, in the current investigation, the screening study was performed to find which EOR method is the most proper method for tertiary oil recovery. For this purpose, intelligent screening method based on Bayesian network (based on Zerafat et al. method [7]) was used to find the proper EOR methods.

A full description of the used method is given elsewhere [7]. In brief, a data bank has been gathered from worldwide EOR/IOR techniques and analyzed using data mining procedure which is then combined with extracted data from previously published screening tables. Bayesian network quantitative learning technique was applied to different data combinations from the data bank to train the network which is to serve as the expert system. The produced expert system is also applied to the gathered data pertaining to 10 Iranian southwest reservoirs. This expert system is based on Bayesian network analysis in order to sort the proper EOR techniques. By inserting several inputs including viscosity, permeability, specific API and reservoir temperature, and depth of reservoir, the used intelligent method demonstrates several possible EOR methods along to the percent of the EOR method efficiency.

\subsection{Recombination}

In general, surface samples are obtained at the separator require collection of high stage separator gas and liquid which must be subsequently recombined in a ratio that corresponds to the relative amounts of gas and liquid produced, as the reservoir fluid travels up through the wellbore and on through the surface separation facilities [21]. The recombination of surface separator samples is achieved by recombining the gas and fluid either to match the measured separator GOR or to match a specified saturation pressure at the reservoir temperature. In cases where the reservoir fluid is known to be highly under saturated, the target saturation pressure may be significantly lower than the actual reservoir pressure and therefore the separator GOR may be a better reservoir fluid characteristic to attempt to match [22].

\section{PVT Tests}

\subsection{Constant Composition Expansion (CCE)}

As shown schematically in Figure 1, firstly the hydrocarbon fluid sample (oil or gas) metered into a visual PVT cell at reservoir temperature and at a pressure in excess of the initial reservoir pressure. Then, the CCE test was started by lowering the pressure in small increments and recording of changes in volume at each pressure. The procedure is repeated until the cell pressure was reduced to a pressure that is considerably lower than the saturation pressure. The original composition of the fluid in the cell does not change at any time during the test because no material is removed from the cell. The fluid may be either oil or a gas with condensate. If the fluid is oil, the saturation pressure is the bubble point pressure. Finally, the volume of the hydrocarbon system as a function of the cell pressure is reported as the ratio of the reference volume [21].

\subsection{Differential Vaporization}

In general, in the differential liberation process, live oil sample is placed in a PVT cell at reservoir temperature and at a pressure above the bubble point pressure. Then, the solution gas that is liberated from an oil sample during a decline in pressure is continuously removed.

In brief, as shown schematically in Figure 2, the pressure is reduced in steps, usually 10 to 15 pressure levels, and all the liberated gas is removed and its volume is measured at standard conditions. The volume of oil remaining $\mathrm{V}_{\mathrm{L}}$ is also measured at each pressure level [21].

\subsection{Swelling Test}

This test is usually conducted for reservoirs to be depleted under gas injection, miscible type displacement or 

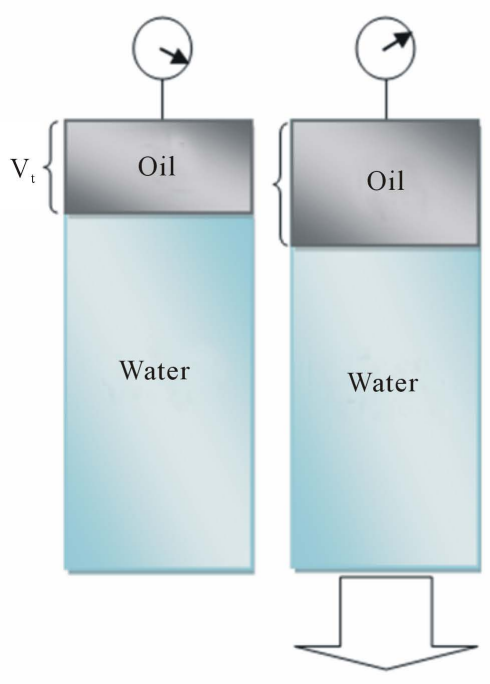

First step

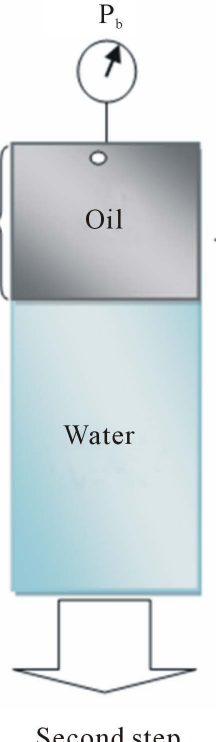

Second step

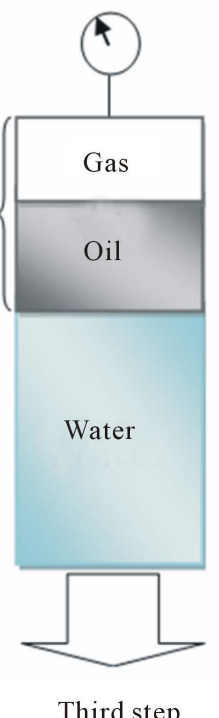

Third step

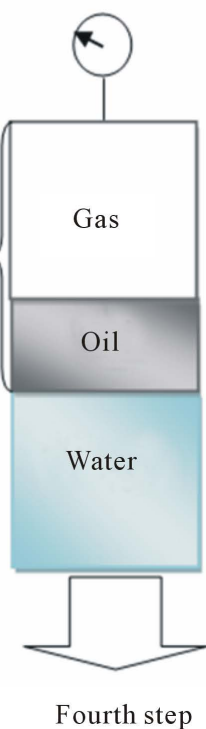

Figure 1. Schematic of the used procedure for constant composition expansion (CCE).

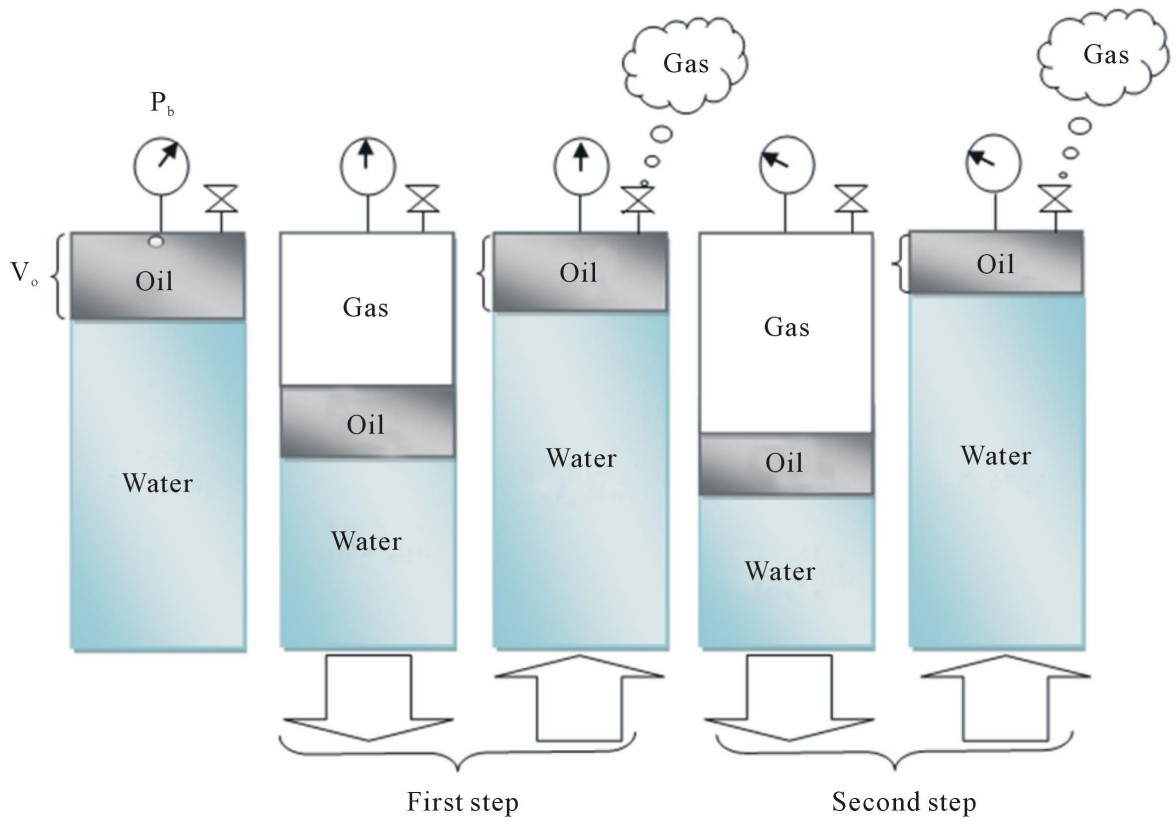

Figure 2. Schematic of the used procedure for differential vaporization or differential liberation (DL).

dry gas cycling. In this test, a gas of known composition, usually similar to the proposed injection gas, is injected in a series of slugs into a reservoir oil sample, as shown in Figure 3. The injection of the first gas slug starts at the bubble point pressure of the reservoir fluid sample and continues until a considerable amount of gas is injected. After each gas addition, the cell is pressured up until only one phase is present [23].

\section{Results and Discussions}

\subsection{Screening of EOR Methods}

Generally, it is not possible to consider the best EOR method based on one or two characteristics of the reservoir. 
The available software capable one to find the proper EOR method using viscosity, permeability, specific API ${ }^{\circ}$ and reservoir temperature, and depth of reservoir at three different modes. The results listed in Table 2 revealed that based on the three different modes, three different methods including miscible $\mathrm{CO}_{2}$, miscible nitrogen and miscible hydrocarbon injection are the most proper EOR methods. In the light of these findings, $\mathrm{CO}_{2}$ and $\mathrm{N}_{2}$ injection on the live crude oil was investigated in the remained stages of this study to reliably check which gas is more efficient for enhanced oil recovery. In addition, the results obtained from the screening method must be corrected using availability of gases and economic and environmental issues.

\subsection{PVT Test}

In this work, recombination of provided gas and oil from separator ( $P=334 \mathrm{psi}$ and $\left.T=100^{\circ} \mathrm{F}\right)$ using GOR of $601 \mathrm{scf} / \mathrm{STB}$ was performed. To examine if the recombination was correctly carried out, the bubble point pressure of the prepared live-crude oil was measured using visual PVT (CCE test) equipment. The obtained results revealed that the bubble point pressure of the recombined live crude oil was about 1727 psi (see Figure 4). In other words, the average absolute relative deviation percent (AARD\%) of the bubble point pressure obtained by prepared crude oil compared to actual sample of live crude oil was about $8 \%$ means the recombined crude oil is well close to reservoir sample.

The differential oil formation volume factors $B_{o}$ from differential liberation (DL) test (commonly called the relative oil volume factors) at all the various pressure levels are calculated by dividing the recorded oil volumes $V_{L}$ by the volume of residual oil $V_{s c}$, or:
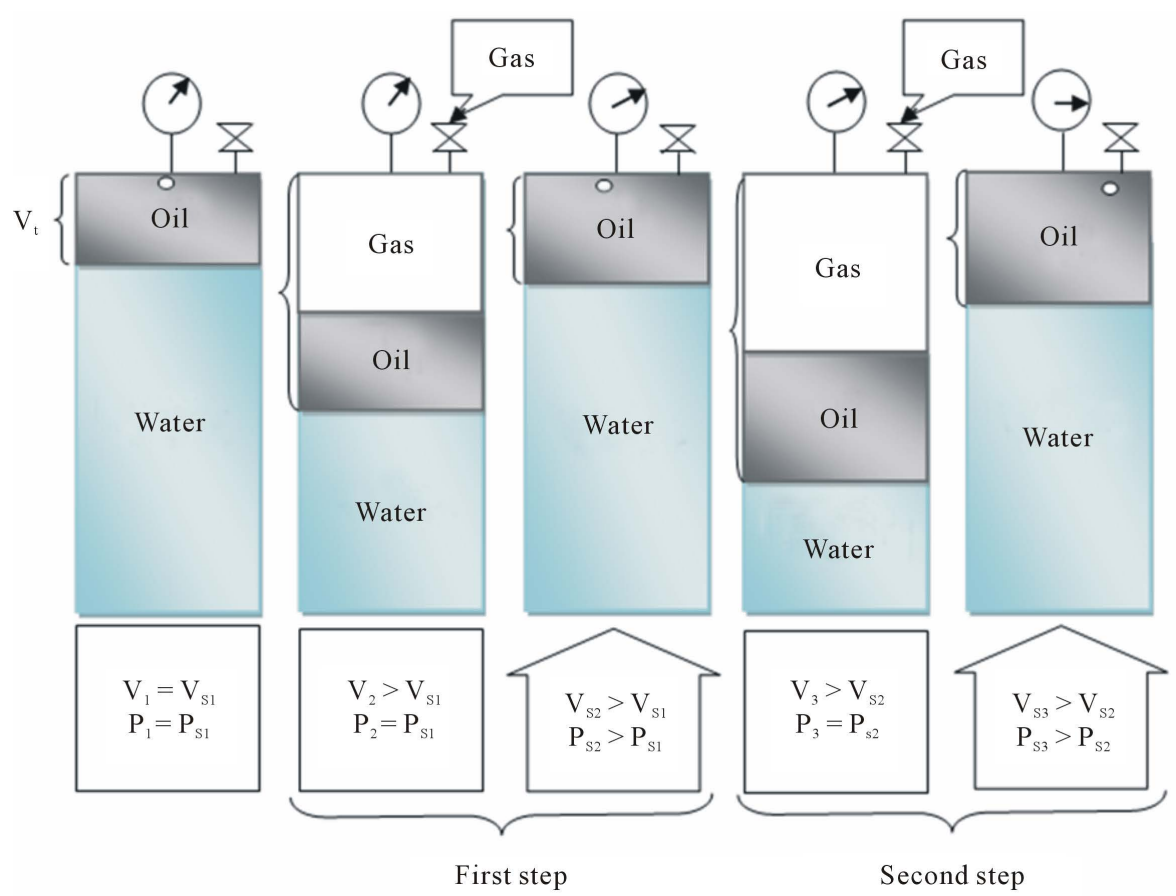

Figure 3. Schematic of the used procedure for swelling test.

Table 2. The results of screening using intelligent software using different modes.

\begin{tabular}{ccccccc}
\hline \multirow{2}{*}{ Method } & \multicolumn{5}{c}{ EOR method } \\
\cline { 2 - 7 } & $\mathbf{N}_{2}$ miscible & Polymer & HC miscible & CO $_{2}$ miscible & Combustion & Steam \\
\hline Taber & 27 & 0 & 27 & 27 & 20 & 0 \\
Field & 0 & 0 & 44 & 52 & 0 & 4 \\
Taber + Field & 10 & 0 & 38 & 43 & 7 & 2 \\
\hline
\end{tabular}




$$
B_{o}=\frac{V_{L}}{V_{s c}}
$$

The $B_{o}$ at pressure greater that bubble point pressure could be obtained by simultaneously using of CCE and DL tests (see Figure 5):

$$
B_{o}=\left(\frac{V_{t}}{V_{\text {sat }}}\right)_{C C E} B_{o D V b} \quad \text { at } P \geq P_{b}
$$

The differential solution gas-oil ratio $R_{s d}$ is also calculated by dividing the volume of gas in solution by the residual oil volume. As illustrated in Figure 5 and Figure 6, the differential relative oil volume $\left(B_{o}\right)$ and the differential gas-oil ratio $\left(R_{s}\right)$ at the bubble-point pressure are $1.47 \mathrm{rbbl} / \mathrm{STB}$ and $600 \mathrm{scf} / \mathrm{STB}$, respectively.

Also, the gas formation volume factor $B_{g}$ (see Figure 7) can be described by the following equation [21]:

$$
B_{g}=0.0282 \frac{z T}{P} \frac{c u f t}{s c f}
$$

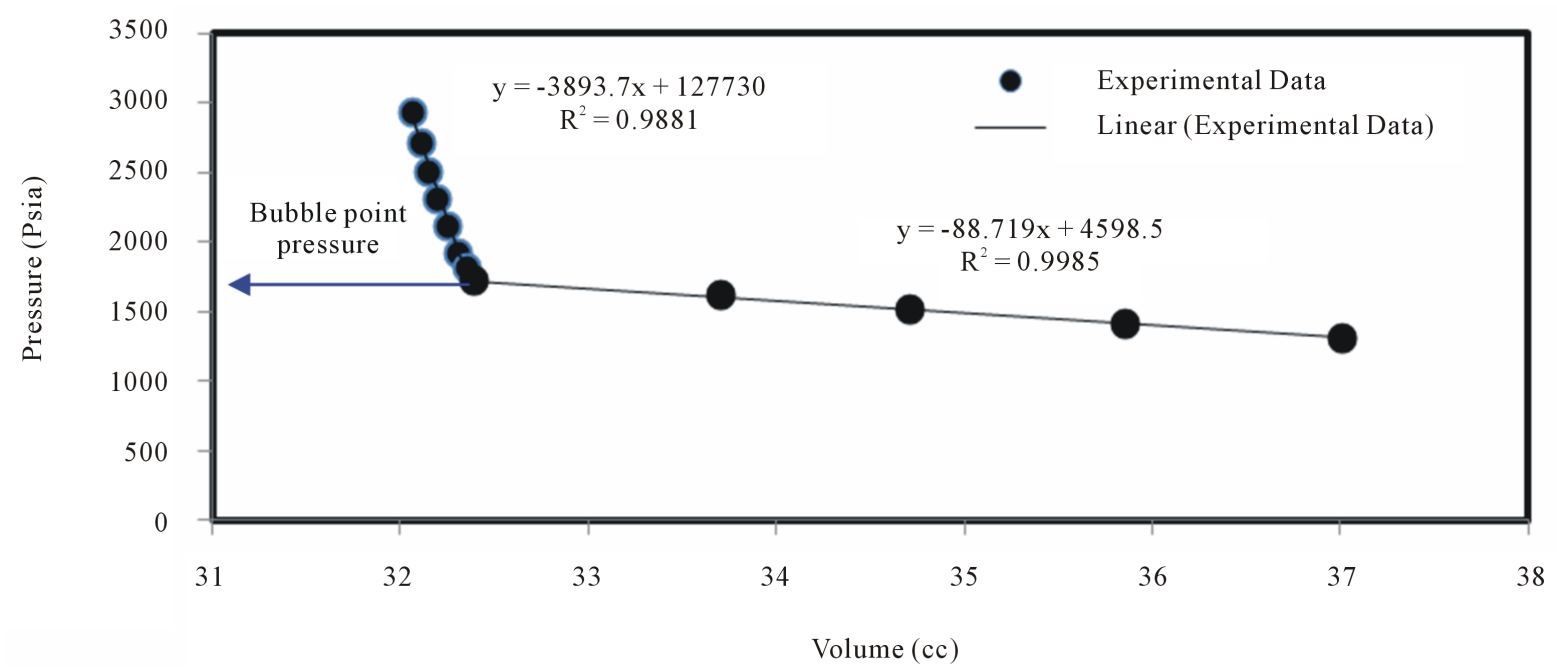

Figure 4. Results obtained from constant composition expansion.

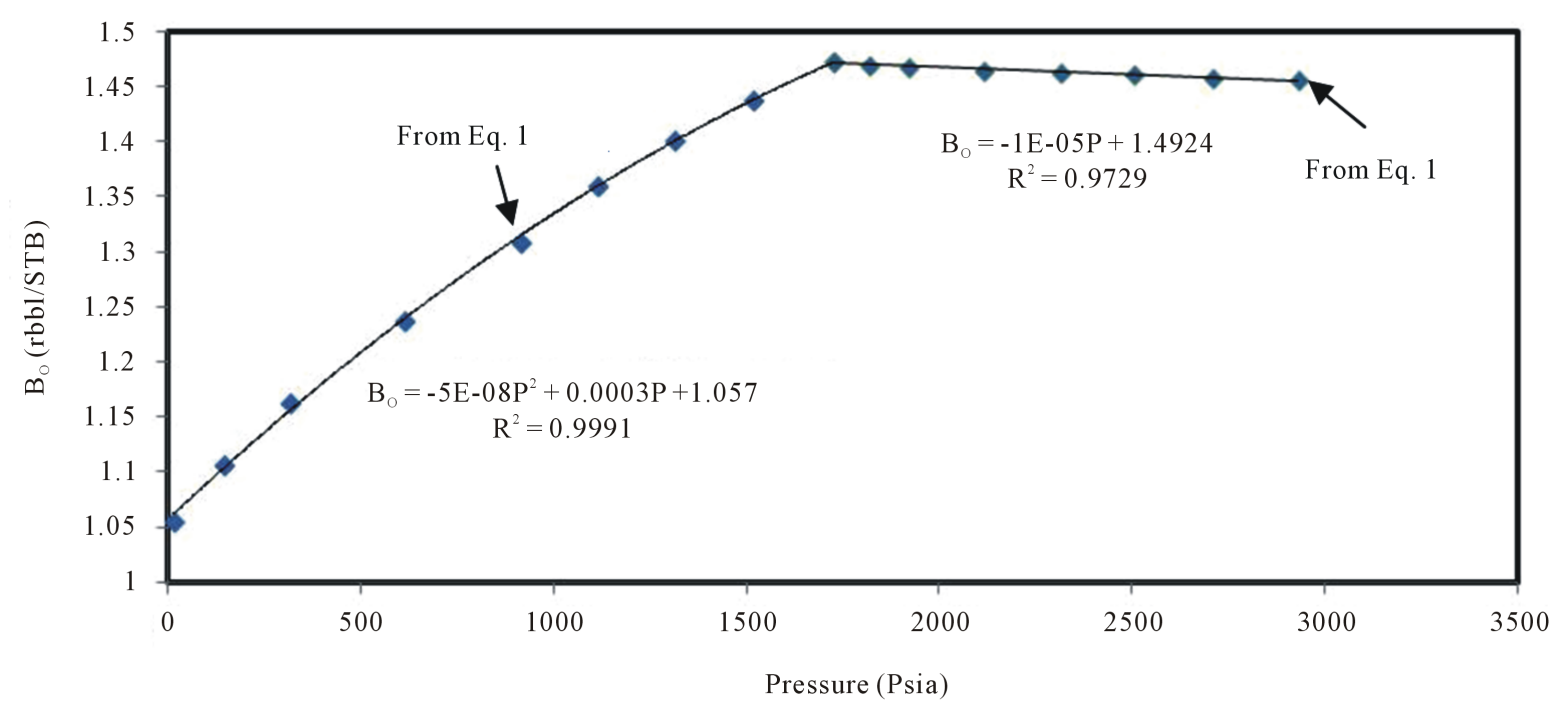

Figure $5 . B_{0}$ of the studied live crude oil as a function of pressure. 


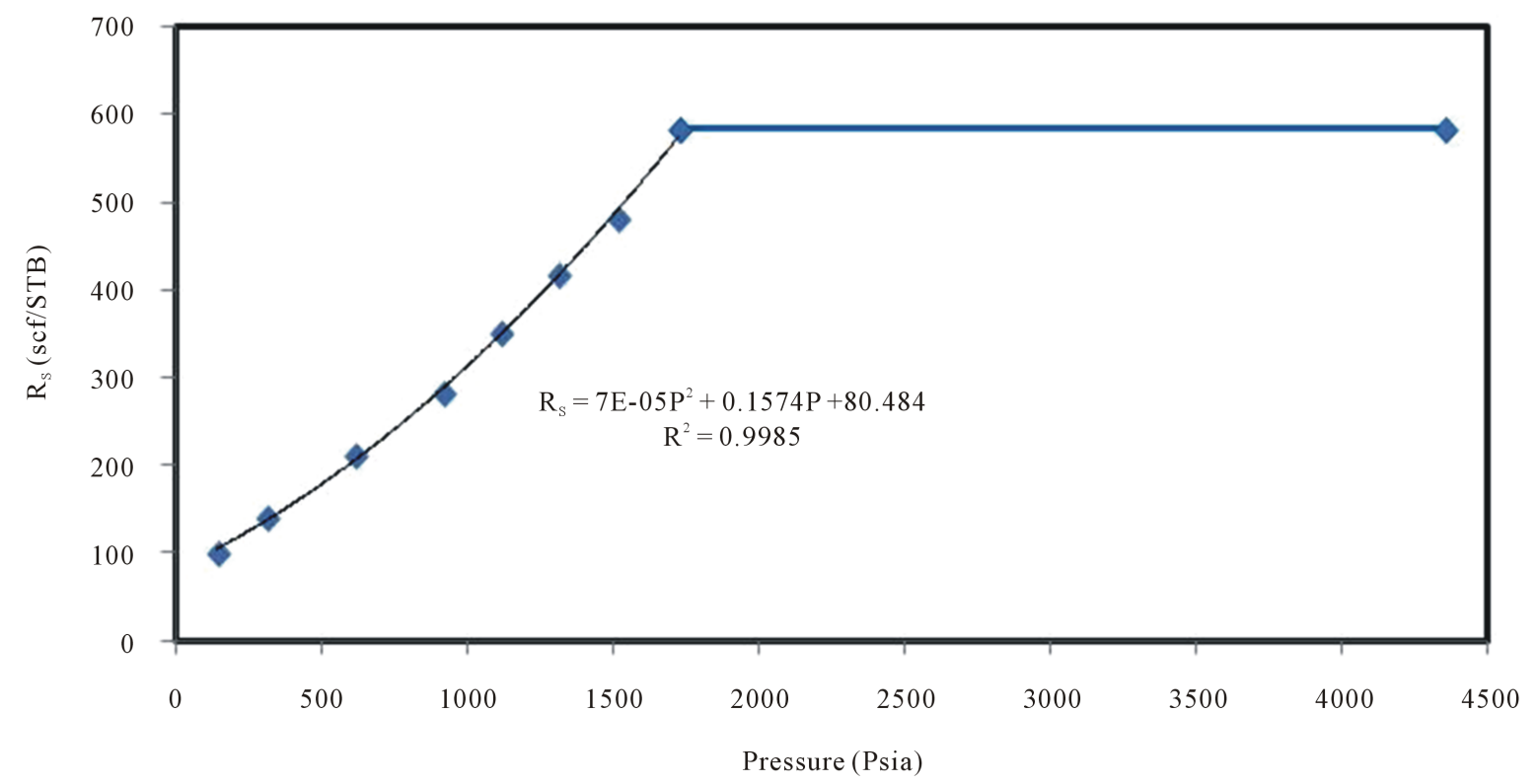

Figure 6. $R_{s}$ for the studied live crude oil as a function of pressure.

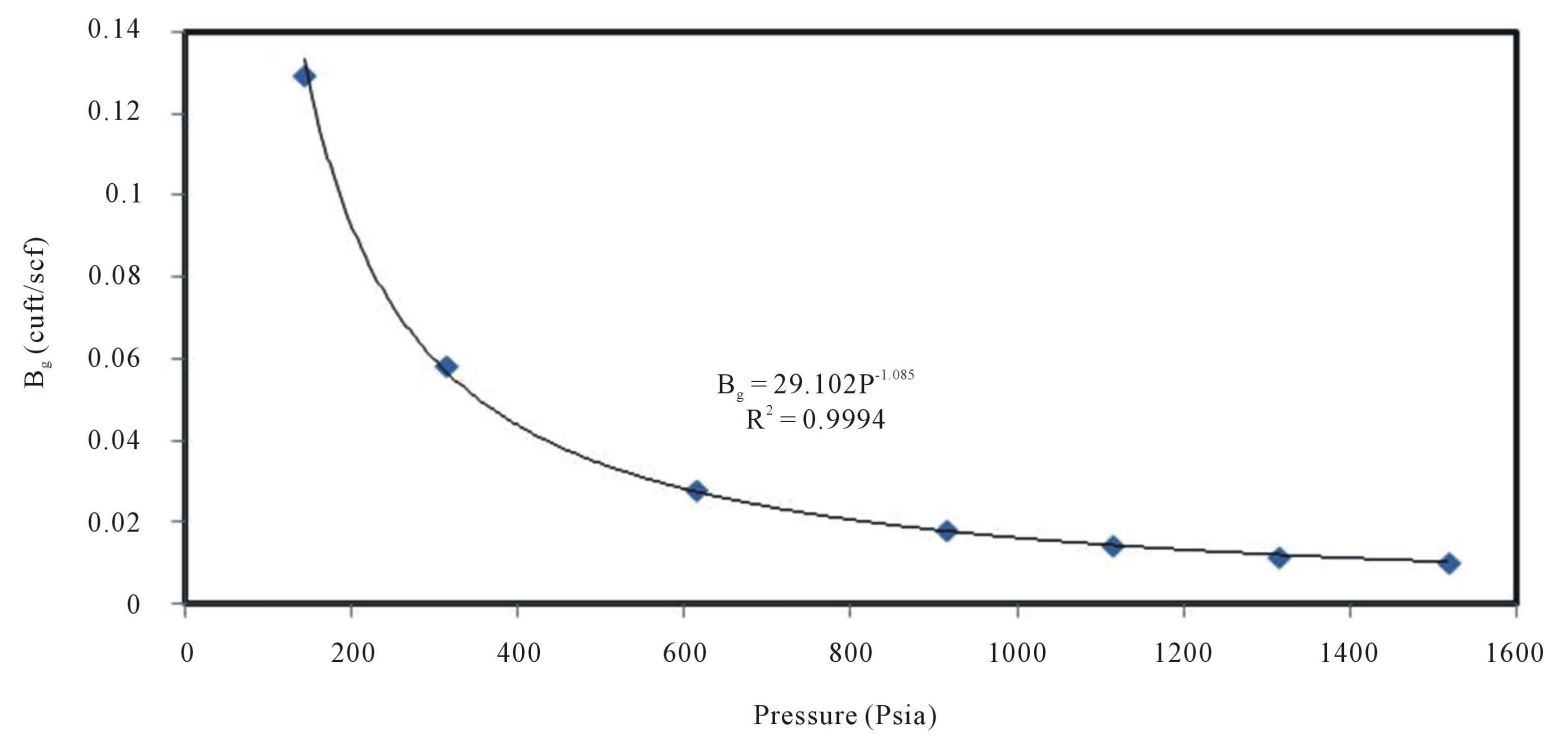

Figure 7. Calculated and predicted $B_{g}$ for the examined live crude oil.

where $B_{g}$ is the gas formation volume factor in $\mathrm{ft}^{3} / \mathrm{scf}, T$ is the temperature in $R, P$ is the cell pressure in psia and $z$ is the gas deviation. The $\mathrm{z}$-factor was calculated from the recorded gas volume measurements as follows:

$$
z=\frac{V_{R} P_{R} T_{s c}}{V_{s c} P_{s c} T_{R}}
$$

where $V_{R}$ is the volume of the liberated gas in the PVT cell at $p$ and $T, V_{s c}$ is the volume of the removed gas at standard, $T_{s c}$ is the standard temperature in $R$ and $P_{s c}$ is the standard pressure in psia.

Finally, the total live crude oil formation factor, $B_{t}$ (see Figure 8) and coefficient of isothermal compressibility, $c_{0}$ (see Figure 9) were successfully calculated from the recorded data points (see Equations (5) to (7)) [21].

$$
B_{t}=B_{o}+B_{g}\left(R_{s b}-R_{s}\right)
$$




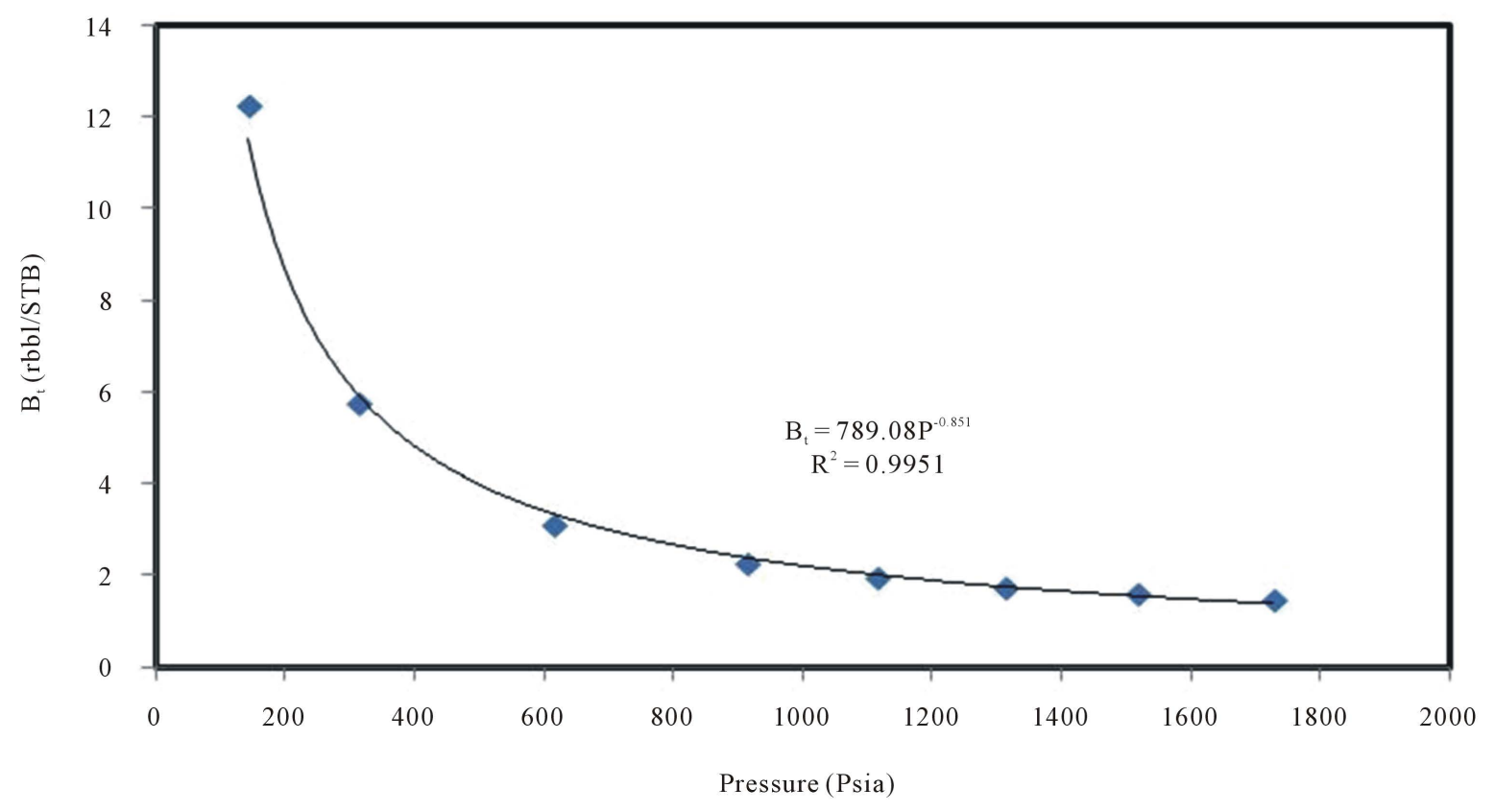

Figure 8. Experimental and predicted values of $B_{t}$.

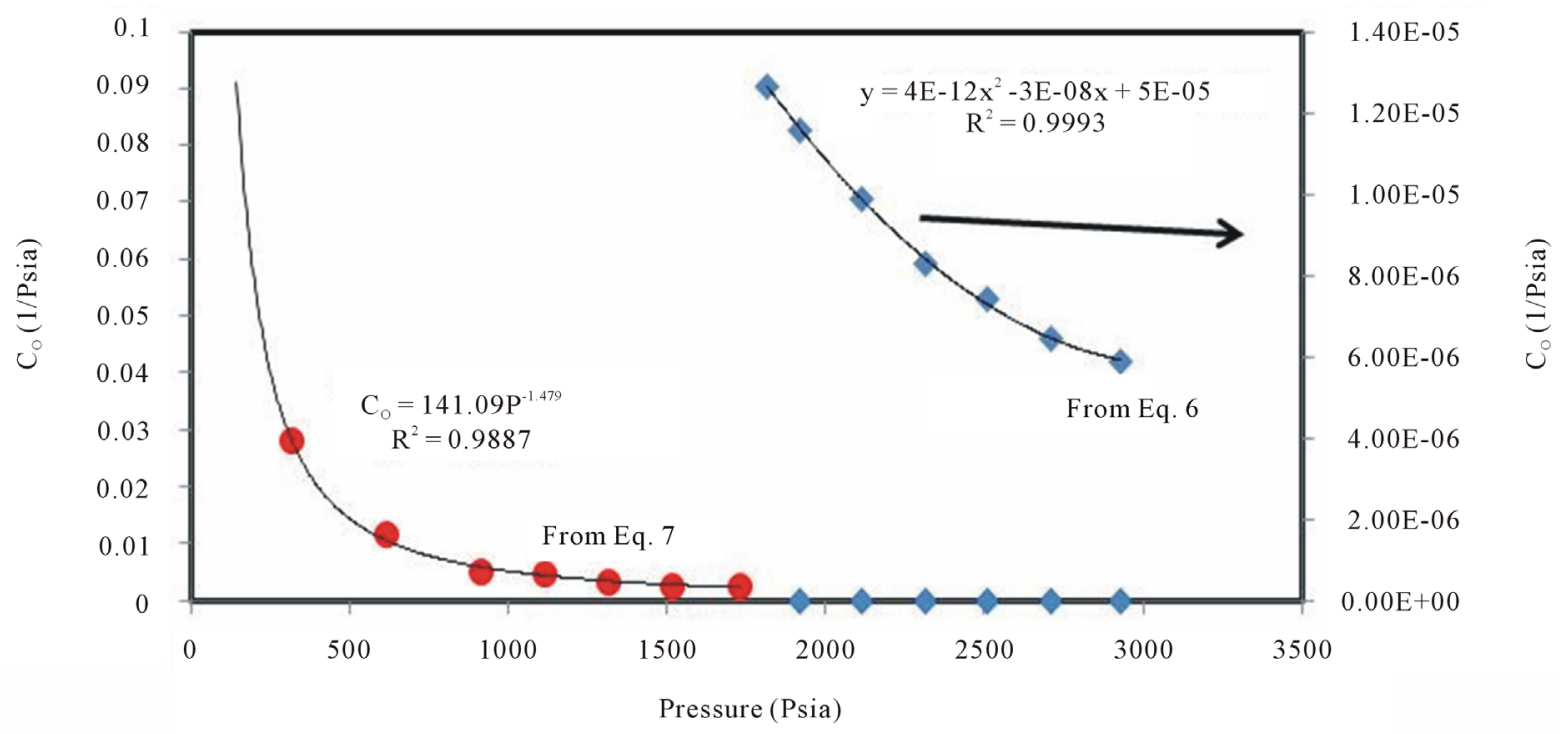

Figure 9. Experimental and predicted values of coefficient of isothermal compressibility (blue and red points obtain from Equation (6) and Equation (7), respectively).

$$
\begin{gathered}
\text { For } P>P_{b}: c_{o}=-\frac{1}{B_{o}}\left[\left(\frac{\partial B_{o}}{\partial P}\right)_{T}-B_{g}\left(\frac{\partial R_{s}}{\partial P}\right)_{T}\right] \\
\text { For } P<P_{b}: c_{0}=\frac{-1}{V_{\text {rel }}} \frac{\partial V_{r e l}}{\partial P}
\end{gathered}
$$

Swelling Test

The live-crude oil was initially metered into visual PVT cell at bubble point pressure of 1727 psi bar and reservoir temperature of $212^{\circ} \mathrm{F}$. After that, injection of $\mathrm{CO}_{2}$ and $\mathrm{N}_{2}$ was begun. As it is demonstrated in Figure 10, 


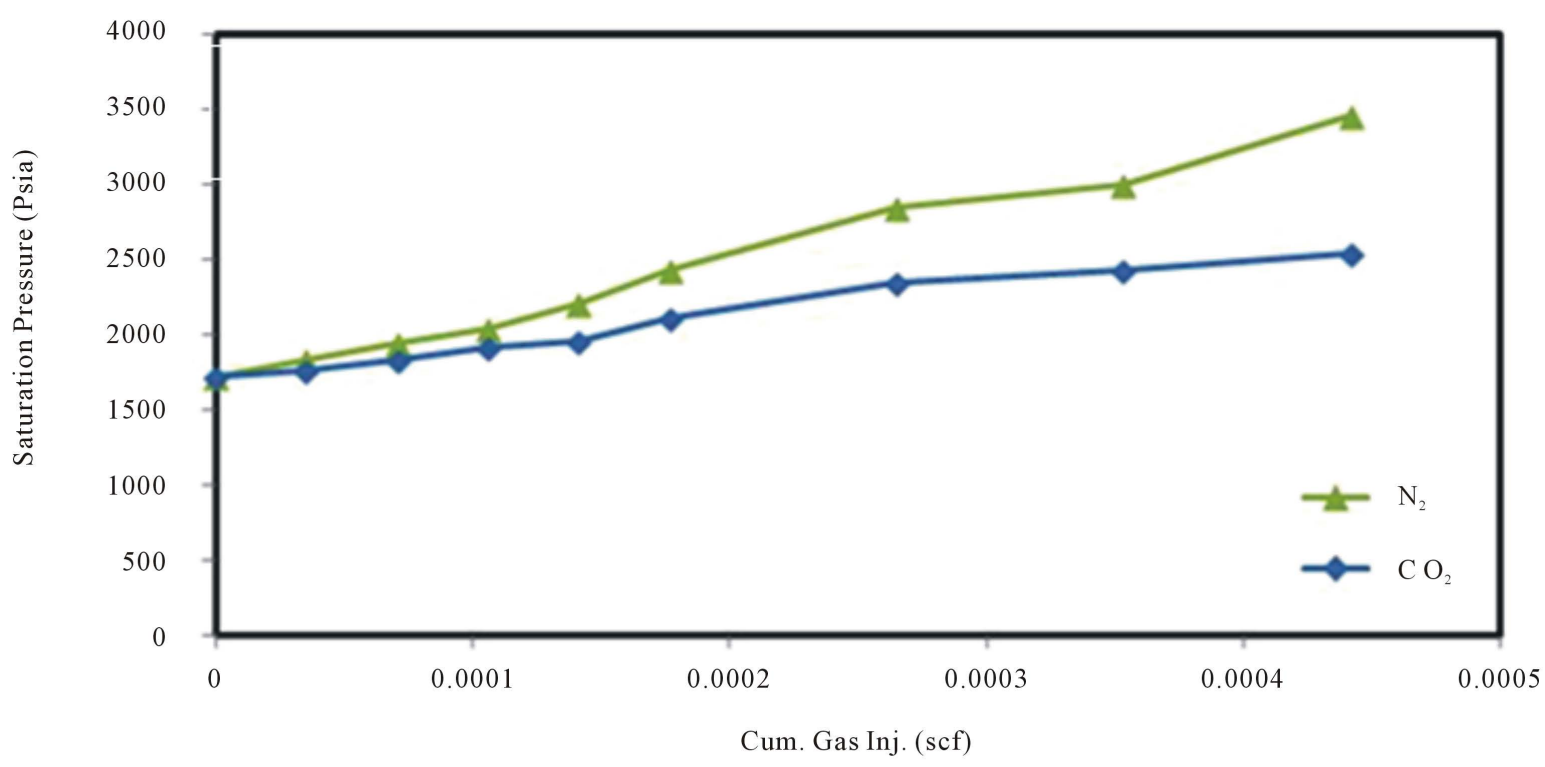

(a)

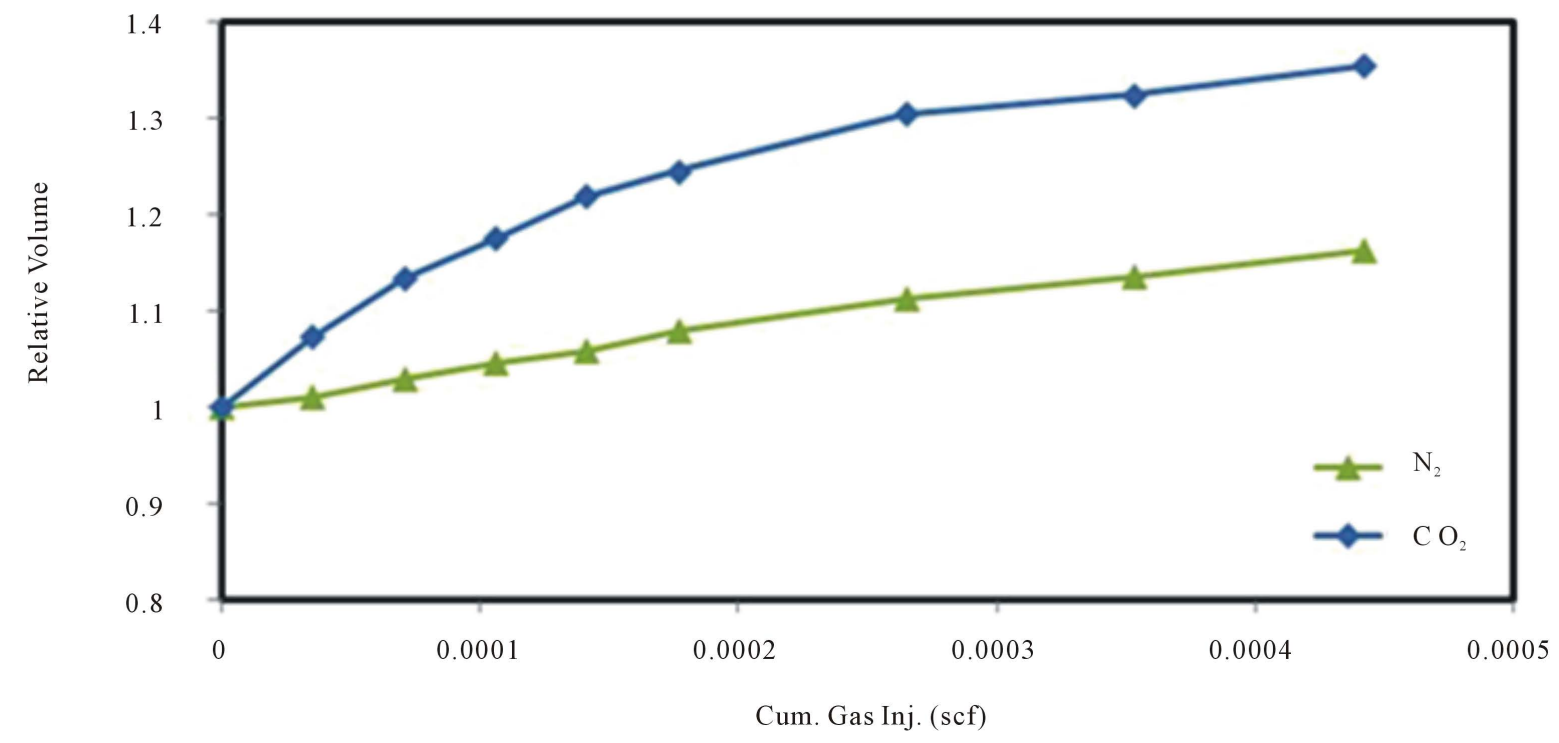

(b)

Figure 10. Comparison between the effect of $\mathrm{CO}_{2}$ and $\mathrm{N}_{2}$ injection on; (a) bubble point pressure, and (b) swelling factor.

injection of $\mathrm{CO}_{2}$ can increase the relative volume (expansion) to 1.35 at high $\mathrm{CO}_{2}$ saturation pressure while the injection of $\mathrm{N}_{2}$ cannot significantly increase the swelling factor even at high saturation pressures. Generally, it is obvious that not only $\mathrm{CO}_{2}$ leads to the lower bubble point pressure compared with $\mathrm{N}_{2}$, but also leads to higher swelling factor (see Figure 10). Totally, it can be concluded that it is possible to have higher oil recovery by injection of $\mathrm{CO}_{2}$ instead of $\mathrm{N}_{2}$. It should be mentioned that, the $\mathrm{N}_{2}$ injection leads to a significant increase in the bubble point pressure of the crude oil which is not desired in the gas injection process for EOR methods. In addition, the fluid most commonly used for miscible displacement is $\mathrm{CO}_{2}$ and $\mathrm{N}_{2}$ because it reduces the oil viscosity and is less expensive than liquefied petroleum gas [24]. Since the miscibility conditions of $\mathrm{N}_{2}$ is very difficult to be achieve in most of the cases, $\mathrm{CO}_{2}$ injection has been gain an increasingly attention. On the other hand, due to the environmental concern of greenhouse gas effect on the global warming $\mathrm{CO}_{2}$ capture and sequestration is being considered as one of the most attractive research area during the past decade [25]. 


\section{Conclusions}

The summary of the main obtained results is as follows:

1) Based on the intelligent screening software, $\mathrm{CO}_{2}$ injection, hydrocarbon miscible injection and $\mathrm{N}_{2}$ injection are the main EOR methods which may lead to the higher tertiary oil recovery.

2) Swelling tests performed by $\mathrm{N}_{2} \mathrm{I}$ and $\mathrm{CO}_{2} \mathrm{I}$ revealed that the $\mathrm{CO}_{2} \mathrm{I}$ leads to the higher swelling factor compared with $\mathrm{N}_{2} \mathrm{I}$.

3) Considering that volume shrinkage factor was about 1.4, it can be concluded that the studied reservoir has about 750 million barrels of STB original oil which can be produced.

4) Totally according to high amount of reservoir reserve, screening results, performed tests, carbon capture and storage and availability of $\mathrm{CO}_{2}$ and its effect on the swelling of live crude oil which is one of the most important mechanisms of oil production, it seems that $\mathrm{CO}_{2} \mathrm{I}$ can be the most proper method for EOR purposes for the studied reservoir.

\section{References}

[1] Lashkarbolooki, M., Ayatollahi, S. and Riazi, M. (2014) The Impacts of Aqueous Ions on Interfacial Tension and Wettability of an Asphaltenic-Acidic Crude Oil Reservoir during Smart Water Injection. Journal of Chemical and Engineering Data, 59, 3624. http://dx.doi.org/10.1021/je500730e

[2] Lashkarbolooki, M., Ayatollahi, S. and Riazi, M. (2014) Effect of Salinity, Resin, and Asphaltene on the Surface Properties of Acidic Crude Oil/Smart Water/Rock System. Energy Fuels, 28, 6820-6829. http://dx.doi.org/10.1021/ef5015692

[3] Kamari, A., Nikookar, M., Sahranavard, L. and Mohammadi, A.H. (2014) Efficient Screening of Enhanced Oil Recovery Methods and Predictive Economic Analysis. Neural Computing and Applications, 25, 815-824. http://dx.doi.org/10.1007/s00521-014-1553-9

[4] Green, D.W. and Willhite, G.P. (1998) Enhanced Oil Recovery, SPE Textbook Series, Volume 6. Society of Petroleum Engineers, Richardson, Texas.

[5] Chukwudeme, E.A. and Hamouda, A.A. (2009) Enhanced Oil Recovery (EOR) by Miscible $\mathrm{CO}_{2}$ and Water Flooding of Asphaltenic and Non-Asphaltenic Oils. Energies, 2, 714-737. http://dx.doi.org/10.3390/en20300714

[6] Siemek, J., Nagy, S. and Zawisza, L. (2006) Acta Montanistica Slovaca, 1, 172.

[7] Zerafat, M.M., Ayatollahi, S., Mehranbod, N. and Barzegari, D. (2011) SPE Enhanced Oil Recovery Conference, Kuala Lumpur, 19-21 July 2011.

[8] Aladasani, A. and Bai, N. (2010) Proceeding of the CPS/SPE International Oil and Gas Conference and Exhibition, Beijing.

[9] Barzegari, D., Ayatollahi, S., Zerafat, M.M. and Roosta, A.A. (2010) Proceeding of $14^{\text {th }}$ International Oil, Gas and Petrochemical Congress, Tehran.

[10] Dickson, J.L., Leahy-Dios, A. and Wylie, P.L. (2010) Proceeding of SPE Improved Oil Recovery Symposium, Tulsa.

[11] Gharbi, R.B.C. (2000) An Expert System for Selecting and Designing EOR Processes. Journal of Petroleum Science and Engineering, 27, 33-47. http://dx.doi.org/10.1016/S0920-4105(00)00049-8

[12] Gharbi, R. (2005) Application of an Expert System to Optimize Reservoir Performance. Journal of Petroleum Science and Engineering, 49, 261-273. http://dx.doi.org/10.1016/j.petrol.2005.05.008

[13] Guerillot, D.R. (1988) The Symposium on Petroleum Industry Applications of Microcomputers, San Jose, 27-29 June 1988.

[14] Lee, J.Y., Shin, H.J. and Lim, J.S. (2011) Selection and Evaluation of Enhanced Oil Recovery Method Using Artificial Neural Network. Geosystem Engineering, 14, 157-164. http://dx.doi.org/10.1080/12269328.2011.10541345

[15] Parkinson, W.J., Luger, G.F., Bretz, R.E. and Osowski, J. (1994) Using an Expert System to Explore Enhanced Oil Recovery Methods. Computers \& Electrical Engineering, 20, 181-197. http://dx.doi.org/10.1016/0045-7906(94)90029-9

[16] Taber, J.J. and Martin, F.D. (1983) Proceeding of the 58th Annual Technical Conference and Exhibition, San Francisco.

[17] Taber, J.J., Martin, F.D. and Seright, R.S. (1997) Proceeding of the SPE/DOE Improved Oil Recovery Symposium, Tulsa.

[18] Taber, J.J., Martin, F.D. and Seright, R.S. (1997) EOR Screening Criteria Revisited—Part 2: Applications and Impact 
of Oil Prices. Proceeding of the SPE/DOE Improved Oil Recovery Symposium, Tulsa.

[19] Al Adsani, A. and Bai, B. (2011) Analysis of EOR Projects and Updated Screening Criteria. Journal of Petroleum Science and Engineering, 79, 10-24. http://dx.doi.org/10.1016/j.petrol.2011.07.005

[20] Goodlett, G.O., Honarpour, F.T., Chung, F.T. and Sarathi, P.S. (1986) Paper SPE 15172, The Rocky Mountain Regional Meeting, Billings, 19-21 May 1986.

[21] McCain, W.D. (1990) The Properties of Petroleum Fluids. 2nd Edition, PennWell Books, PennWell Publishing Company, Tulsa.

[22] Strong, J., Thomas, F.B. and Bennion, D.B. (1993) The CIM 1993 Annual Technical Conference in Calgary, 9-12 May 1993, Petroleum Society of CIM, Paper NO. CIM 93-54.

[23] Sequeira, D.S. (2006) Compositional Effects on Gas-Oil Interfacial Tension and Miscibility at Reservoir Conditions. Master of Science Thesis, Louisiana State University, Baton Rouge.

[24] Willhite, G.P. (1986) Waterflooding: Society of Petroleum Engineers. Richardson.

[25] Zheng, B. and Xu, J. (2014) Carbon Capture and Storage Development Trends from a Techno-Paradigm Perspective. Energies, 7, 5221-5250. http://dx.doi.org/10.3390/en7085221 